\title{
Pharmacogenetics and Clinical Gastroenterology
}

\author{
RAYMOND C. GIVENS*, ${ }^{\ddagger}$ and PAUL B. WATKINS* \\ *General Clinical Research Center, University of North Carolina at Chapel Hill, Chapel Hill, North Carolina; \\ and ${ }^{\ddagger}$ Duke University School of Medicine, Durham, North Carolina
}

Many drugs exhibit variable efficacy and toxicity. Pharmacogenetics explores the genetic underpinnings of variable drug response. Pharmacogenetic testing is beginning to enter the clinic and will have a significant impact on the practice of clinical gastroenterology. Thiopurine S-methyltransferase screening, which will likely become routine for thiopurine recipients, illustrates the promise and limitations of pharmacogenetics. Testing for variation in other drug metabolism pathways may also become important. Pharmacogenetics will complement but not replace traditional methods for choosing drugs and for selecting dosing regimens for narrowtherapeutic-index drugs.

$\mathrm{P}$ harmacogenetics probes the genetics of drug response. Pharmacogenomics, often mentioned interchangeably with pharmacogenetics, is the genome-wide identification of multiple drug response determinants. ${ }^{1}$ In general, a pharmacogenetic analysis considers the contribution to a drug response of a small number of genes. ${ }^{1,2}$ Clinical laboratories generally perform singlegene analysis, so pharmacogenetics is the more appropriate term for clinical drug response testing.

A fundamental pharmacogenetic concept is that a particular drug response is influenced by a limited number of genes whose products include drug-metabolizing enzymes, receptors, and transporters. For single-gene testing to be useful, variation in response to a drug must largely reflect functional differences between products of a gene that exists in a limited number of versions, or alleles. An individual generally has 2 identical or dissimilar alleles for a gene-one maternal, the other paternal. In the simplest case, only 2 unique alleles for a gene exist among a population, one encoding a fully functional product and the other a dysfunctional product. An individual's gene product activity is then high, intermediate, or low-reflecting the respective presence of 2,1 , or 0 functional alleles. A gene is considered polymorphic if the frequency of the low-function allele is relatively high, generally $1 \%$ or greater.
Drug response determinants are broadly regarded as pharmacodynamic or pharmacokinetic, although these categories overlap. Pharmacodynamic determinants control drug target responsiveness to fixed drug concentrations. $^{3}$ Pharmacodynamic variation might reflect polymorphism among genes encoding drug receptors, transporters, drug targets, and gene products whose activities are central to disease progression. ${ }^{3,4}$ Genotyping for most of these genes has yet to reach routine clinical application. Clinical pharmacodynamic testing is routine in 2 areas: in infectious disease, pathogen genotype (e.g., for hepatitis $C$ and human immunodeficiency viruses) may associate with therapeutic response; in oncology, breast tumor HER2/neu expression predicts efficacy of the anti-HER2 monoclonal antibody Herceptin (trastuzumab) ${ }^{5}$ and gastrointestinal stromal tumor $c$-Kit expression predicts response to the tyrosine kinase inhibitor Gleevec (imatinib mesylate). ${ }^{6}$ In these instances, the tumor or pathogen is tested but not the patient, per se; the term pharmacogenetics generally refers to human host variation, so tumor and pathogen genetics will not be discussed here.

Pharmacokinetics is the study of drug or metabolite concentrations in plasma or other tissue compartments as a function of time and drug dose. ${ }^{3}$ Interpatient pharmacokinetic variation reflects differences in drug absorption, distribution, metabolism, and excretion, which modulate availability of the drug or metabolite at target molecules. Pharmacokinetic variation is clinically important if it results in failure of therapeutic drug response in some patients and/or toxic responses in others. This is

Abbreviations used in this paper: 5-FU, 5-fluorouracil; 6-MP, 6-mercaptopurine; 6-MMP, 6-methylmercaptopurine; 6-TGNs, 6-thioguanine nucleotides; AlH, autoimmune hepatitis; ALL, acute lymphoblastic leukemia; AZA, azathioprine; EMs, extensive metabolizers; HGPRT, hypoxanthine guanine phosphoribosyltransferase; RBCs, red blood cells; PMs, poor metabolizers; PPIs, proton pump inhibitors; XO, xanthine oxidase.

(C) $\mathbf{2 0 0 3}$ by the American Gastroenterological Association 0016-5085/03/\$30.00 doi:10.1016/S0016-5085(03)00683-8 
most likely to be the case with drugs that produce benefit without toxicity over a narrow range of blood or tissue levels (i.e., drugs with narrow therapeutic indices). ${ }^{7} \mathrm{Re}-$ cent progress has identified specific enzymes and transporters that underlie pharmacokinetic variability. This review focuses upon polymorphic enzyme activities that underlie clinically important drug responses. We have selected examples of interest to gastroenterologists.

\section{TPMT}

The polymorphic thiopurine S-methyltransferase (TPMT) inactivates 6-mercaptopurine (6-MP), which is used to treat acute lymphoblastic leukemia (ALL). ${ }^{8}$ Gastroenterologists prescribe 6-MP and its prodrug azathioprine (AZA) as second-line therapy for Crohn's disease ${ }^{9,10}$ and ulcerative colitis, ${ }^{11,12}$ in combination therapy to prevent liver transplant rejection, ${ }^{13}$ and as treatment for autoimmune hepatitis (AIH). ${ }^{14}$

As shown in Figure 1, AZA is nonenzymatically converted to 6-MP. Xanthine oxidase (XO) then catalyzes presystemic (first-pass) oxidation of a portion of the 6-MP pool to the inactive 6-thiouric acid. ${ }^{11}$ The 6-thioguanine nucleotides (6-TGNs), the active metabolites of the unoxidized 6-MP, are downstream products of the purine salvage enzyme hypoxanthine guanine phosphoribosyltransferase (HGPRT). ${ }^{8}$ TPMT produces therapeutically inactive 6-methylmercaptopurine (6-MMP) and competes with HGPRT for 6-MP substrate. XO or TPMT activity thus limits 6-TGN production. 6-TGNs exert therapeutic and toxic hematologic effects ${ }^{15}$ by integrating into DNA, thus interrupting replication, and by inhibiting de novo purine synthesis. ${ }^{16}$ Hematopoietic tissues lack XO activity and depend on TPMT to limit

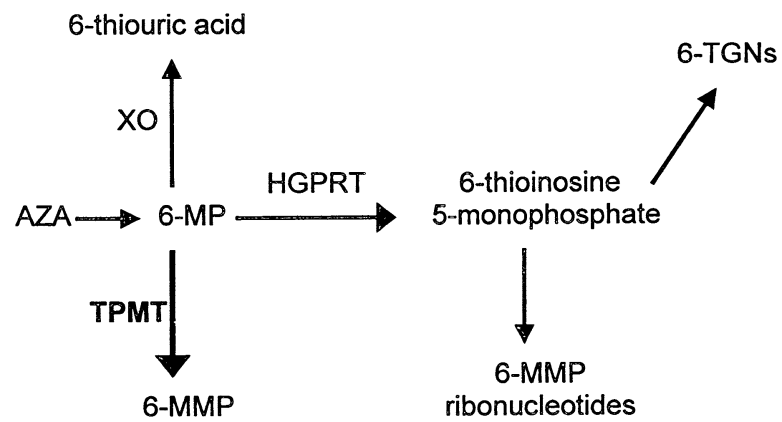

Figure 1. Thiopurine metabolism. Azathioprine (AZA) is non-enzymatically converted to 6-mercaptopurine (6-MP), which is a substrate for 3 main competing enzymes. Hypoxanthine guanine phosphoribosyltransferase (HGPRT) initiates production of the active 6-thioguanine nucleotides (6-TGNs), while xanthine oxidase (XO) and thiopurine S-methyltransferase (TPMT) both inactivate 6-MP by converting it to 6-thiouric acid and 6-methylmercaptopurine (6-MMP), respectively. Polymorphic TPMT activity is the major heritable determinant of variable thiopurine metabolism.

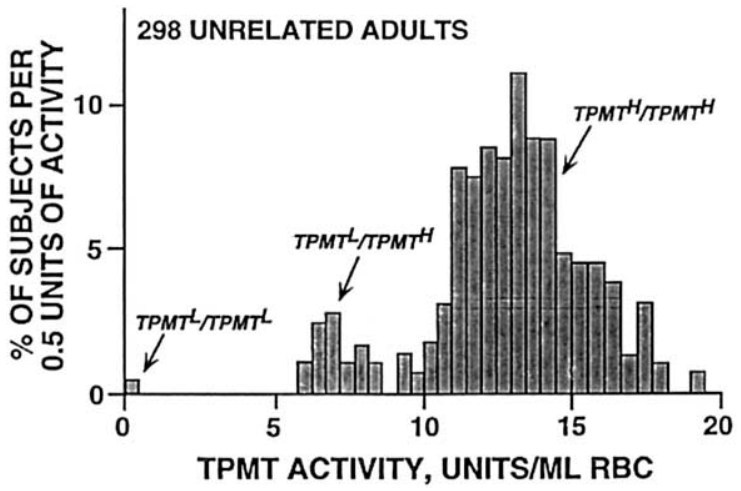

Figure 2. Trimodal Distribution of TPMT Activity in RBCs. The observation of 3 groups of TPMT activity among Caucasian subjects implies codominant inheritance. Low or deficient activity, seen among $0.3 \%$ of subjects, represents a homozygous low-expressor genotype (TPMTL/ TPMTL); intermediate activity (11\%) indicates heterozygosity (TPMTL/ $T P M T^{H}$ ); and high activity (89\%) indicates a homozygous high-expressor genotype $\left(T P M T^{H} / T_{P M T^{H}}\right)$. Reprinted from Weinshilboum ${ }^{31}$ with permission.

6-TGN production and myelotoxicity. ${ }^{17}$ TPMT activity can be conveniently measured radiochemically or chromatographically in peripheral red blood cells (RBCs). ${ }^{16}$ $\mathrm{XO}$ appears not to be polymorphic, ${ }^{18}$ so TPMT is the major heritable determinant of variable thiopurine response.

The consequences of TPMT deficiency are best defined in pediatric ALL, for which oral 6-MP is part of remission-induction and -maintenance protocols. ${ }^{19}$ Therapeutic success is tethered by serious and sometimes fatal hematologic toxicity ${ }^{20}$ among some patients treated with the standard ALL 6-MP dose $\left(75 \mathrm{mg} / \mathrm{m}^{2}\right.$ body surface area per day). Toxicity associates with deficient TPMT activity: deficient- or intermediate-activity patients are over-represented among the thiopurine-intolerant. ${ }^{19,21}$ Low RBC TPMT activity predicts high blood 6-TGN concentrations and high activity predicts low concentrations. $^{22,23}$ TPMT activity measured in RBCs or inferred from genotype associates positively with duration of full-dose tolerance and negatively with risk of myelosuppression $^{23}$ and cumulative incidence of 6-MP dose reduction due to toxicity, ${ }^{19}$ i.e., lower activity confers greater risk. TPMT assessment identifies those who should receive a reduced dose: to avoid toxicity, TPMT-deficient ALL patients must be treated with 10-to-15-fold lower thiopurine doses. ${ }^{17,19,24}$

TPMT activity is trimodally distributed among Caucasians and African-Americans (Figure 2): $89 \%$ of each population has high activity ( $>10$ units of activity per $\mathrm{mL}$ of $\mathrm{RBCs}$ ), $11 \%$ intermediate ( 5 to $10 \mathrm{U} / \mathrm{mL}$ ), and $0.3 \%$ low $(<5 \mathrm{U} / \mathrm{mL} \text {; Figure } 2)^{25}$; current Mayo Clinic reference values are $>15 \mathrm{U} / \mathrm{mL}, 6.3$ to $15 \mathrm{U} / \mathrm{mL}$, and $<6.3 \mathrm{U} / \mathrm{mL}$, respectively. ${ }^{26}$ Relative activities corre- 
spond to the respective presence of 2,1 , and 0 functional alleles. Median activity, however, is $20 \%$ lower among African-Americans. ${ }^{27}$ Activity distributes unimodally among Koreans ${ }^{28,29}$ and bimodally among Chinese, who also show a lower frequency (4\%) of low or intermediate activity. ${ }^{30}$

The bulk of TPMT variability is explained by the variant TPMT alleles described to date. ${ }^{31}$ The $* 2,3 A$, $* 3 B, * 3 C, * 3 D, * 4, * 5$ and $* 6$ alleles result from single nucleotide polymorphisms (SNPs) in the TPMT gene. The SNP underlying $* 4$ ablates a splice site and that causing $* 3 D$ produces a premature stop codon; the rest produce amino acid substitutions in rapidly degraded proteins. ${ }^{24,32,33}$ As much as $90 \%$ or more of variants among Caucasians are represented by $* 2, * 3 C$, and $* 3 A$ (which results from the simultaneous presence of the $* 3 B$ and $* 3 C$ SNPs), ${ }^{34,35}$ But allelic frequencies vary significantly between populations: $* 3 A$, the most common variant among Caucasians, is less frequent than $* 3 C$ among African-Americans and is rare among East Asians. ${ }^{35,36}$ Promoter-region variable number tandem repeats may also regulate TPMT expression. ${ }^{37}$

Correlation between TPMT genotype and activity is high: ${ }^{16}$ deficiency is almost invariably explained by a double-variant genotype and the presence of $* 2, * 3 A$, or $* 3 C$ is highly sensitive $(95.2 \%)$ and specific $(100 \%)$ for intermediate activity. ${ }^{38}$ Prospective genotyping may thus identify patients at highest risk for hematologic toxicity. But the importance of rarer alleles and other genetic and nongenetic influences is evinced by a wide range of activity among heterozygotes and non-variant (wild-type) homozygotes. ${ }^{35}$ Thus, usual thiopurine dosing may result in toxicity or inefficacy among low- or high-activity patients, respectively, not identified by genotyping. ${ }^{39}$ For this reason, some advocate measuring RBC TPMT activity-i.e., phenotype-rather than genotype.

TPMT screening also predicts adverse events among non-ALL patients. Median TPMT activity of AZA-intolerant $\mathrm{AIH}$ patients is significantly lower than that of those in remission on AZA monotherapy $\left(2 \mathrm{mg} \cdot \mathrm{kg}^{-1}\right.$. day $^{-1}$ ), which in turn is lower than that of those requiring steroids in addition to AZA. ${ }^{40}$ TPMT-heterozygous rheumatic disease patients treated with AZA (2-3 mg • $\mathrm{kg}^{-1} \cdot \mathrm{day}^{-1}$ ) have shown a higher incidence of leukopenia and a markedly lower duration of tolerated therapy ( 2 vs. 39 weeks) relative to those without variant alleles. ${ }^{41}$ Screening may also predict inefficacy: as in ALL, ${ }^{31}$ there is the potential for undertreatment of high-TPMT IBD patients, ${ }^{42}$ who have a lower toxicity risk but may have a higher risk of drug failure or disease relapse. ${ }^{8,12}$
The predictive utility of TPMT genotype or phenotype in gastroenterology, however, is unproven. In addition to myelotoxicity, thiopurines may also cause potentially dose-limiting gastrointestinal toxicities. Although the incidence of hepatotoxicity correlates with 6-MMP levels, ${ }^{19,43,44}$ it is not predicted by TPMT genotype. ${ }^{45}$ Among thiopurine-treated IBD patients, those with variant TPMT alleles are a minority among neutropenia cases, ${ }^{43,46}$ indicating the importance of other factors. Furthermore, close monitoring of transplant recipient blood counts generally detects neutropenia in time to adjust dosing. It is also possible to escalate dose while monitoring for toxicity. In a "start low, go slow" approach, patients may begin AZA or 6-MP at 0.5-1.5 $\mathrm{mg} \cdot \mathrm{kg}^{-1} \cdot \mathrm{day}^{-1}$ or $0.25-0.5 \mathrm{mg} \cdot \mathrm{kg}^{-1} \cdot \mathrm{day}^{-1}$, respectively, which may be slowly increased to the maintenance dose, ${ }^{12}$ typically $2.0-3.0 \mathrm{mg} \cdot \mathrm{kg}^{-1} \cdot \mathrm{day}^{-1}$ for AZA and $1.0-1.5 \mathrm{mg} \cdot \mathrm{kg}^{-1} \cdot \mathrm{day}^{-1}$ for 6-MP. Blood counts may be measured at 2 weeks, 1 month, and 3 months and then every 3 months for the duration of therapy. ${ }^{47}$ Treatment may be discontinued if white blood cell counts fall below $3.0 \times 10^{9} / \mathrm{L}$ or platelets below $120 \times 10^{9} / \mathrm{L}^{12}$ But this conservative approach may result in prolonged insufficient dosing for the highTPMT patient majority ${ }^{48}$ and may prolong time to therapeutic response, which can be delayed by up to 4 months. ${ }^{11}$ Genotype- or phenotype-specific dosing combined with routine assessments such as blood counts might allow more appropriately aggressive regimens.

As mentioned, nongenetic elements may alter apparent TPMT activity and thus limit the utility of genotyping and predictive phenotyping. Patient age and renal function may alter RBC TPMT activity and transfusion within the previous 2 months may produce spurious measurements. ${ }^{24}$ Drug interactions are also important examples of such influences. Coadministration of AZA and mesalamine, often the case for IBD patients, can increase 6-TGN concentrations and raise risk of myelotoxicity; these interactions may reflect reversible mesalamine inhibition of TPMT. ${ }^{31,49}$ Adverse events are more frequent among patients treated both with thiopurines and mesalamines. ${ }^{49,50}$ Therapeutic furosemide concentrations also inhibit TPMT. ${ }^{51}$ In contrast, thiopurine therapy itself may actually increase TPMT activity. ${ }^{31,42,52} \mathrm{XO}$, the other major toxicity-limiting pathway (Figure 1), is inhibited by allopurinol ${ }^{11}$; AZA dose should be reduced by two-thirds or more when the 2 are coprescribed. ${ }^{16}$ Methotrexate may augment 6-MP bioavailability by inhibiting $\mathrm{XO}^{53}$ and may enhance cytotoxicity by inhibiting de novo purine synthesis. ${ }^{39}$ Methotrexate may also increase levels of phosphoribosyl pyrophosphate, an essential component of 
Table 1. Characteristics of Specific Metabolic Pathways

\begin{tabular}{|c|c|c|c|c|c|}
\hline Enzyme & Substrates & Genotype $^{a}$ & Inducers & Inhibitors & Phenotyping tests \\
\hline TPMT & AZA, 6-MP & $>90 \%$ & AZA, 6-MP & Salicylates, furosemide & RBC assay \\
\hline CYP2D6 & $\begin{array}{l}\text { TCAs, SSRIs, codeine, } \\
\text { antipsychotics, nicotine, } \\
\beta \text {-blockers }\end{array}$ & $\sim 80 \%$ & None known & $\begin{array}{l}\text { Fluoxetine, paroxetine, } \\
\text { quinidine }\end{array}$ & $\begin{array}{l}\text { Dextromethorphan urine } \\
\text { test, sparteine urine test }\end{array}$ \\
\hline CYP2C19 & $\begin{array}{l}\text { PPIs, proguanil, } \\
\text { S-mephenytoin }\end{array}$ & $80 \%-100 \%$ & Phenobarbital, rifampicin & None known & Omeprazole clearance \\
\hline CYP3A4 & $\begin{array}{l}\text { Cyclosporine, lovastatin, } \\
\text { nifedipidine, } \\
\text { erythromycin }\end{array}$ & Not available & $\begin{array}{l}\text { Rifampicin, } \\
\text { dexamethasone, } \\
\text { phenobarbital, } \\
\text { phenytoin, } \\
\text { carbamazepine }\end{array}$ & $\begin{array}{l}\text { Azole antifungals, } \\
\text { cimetidine, erythromycin, } \\
\text { grapefruit }\end{array}$ & $\begin{array}{l}\text { Erythromycin breath test, } \\
\text { midazolam clearance }\end{array}$ \\
\hline
\end{tabular}

aPercent of genetically determined poor metabolizers identified by current genetic testing.

the HGPRT mechanism, thereby increasing entrance of 6-MP into the salvage pool. ${ }^{53}$

For these reasons, therapeutic monitoring of 6-TGN concentrations may provide more relevant information than does TPMT phenotype or genotype in some scenarios. Higher 6-TGN levels associate with improved response ${ }^{43,54}$ and with lower disease activity ${ }^{44}$ among pediatric and adult IBD patients; nonresponders tend to have low levels. ${ }^{55}$ Clinical efficacy associates with 6-TGN levels higher than $250 \mathrm{pmol} / 8 \times 10^{8} \mathrm{RBCs}$ in adult colonic and fistulizing CD. ${ }^{54}$ Higher levels, though, also associate with adverse reactions. ${ }^{55}$ Thiopurine metabolite monitoring can also elucidate the basis of non-efficacy: low 6-TGN levels combined with high 6-MMP levels suggest therapeutic resistance due to high TPMT activity; low 6-MMP levels may indicate noncompliance. ${ }^{56}$

The imperfect ability of TPMT genotype or phenotype to predict clinical events suggests they will not obviate attention to routinely assessed clinical parameters but may be useful supplements. In October 2002, members of the Clinical Pharmacology Subcommittee of the Advisory Committee for Pharmaceutical Science (Food and Drug Administration [FDA] Center for Drug Evaluation and Research) recognized the inadequacy of current thiopurine dosing guidelines and endorsed TPMT screening. ${ }^{57}$ It is thus likely that future AZA and 6-MP product labels will include this recommendation. Failure to screen might then entail legal liability should adverse events occur.

\section{CYP2D6}

The hepatic drug-metabolizing enzyme cytochrome $\mathrm{P} 450$ (CYP) 2D6 participates in the elimination of over 100 drugs (Table 1). Individuals are classified as CYP2D6 ultrarapid metabolizers, extensive metabolizers (EMs), intermediate metabolizers, and poor metabolizers (PMs) corresponding to the respective presence of at least
3 (due to gene multiplication), 2, 1 , and 0 functional alleles. CYP2D6 is not expressed in blood cells-phenotyping is performed by administering "probe" drugs such as the antihypertensive debrisoquin, the oxytocic sparteine, or the antitussive dextromethorphan. Drug clearance or urinary metabolite-to-parent drug ratio is then measured. Probe-based tests are still experimental and are not commercially available.

Roughly 75 CYP2D6 alleles have been identified.58 Functional alleles include $* 1, * 2, * 9, * 10$, and $* 17$. The most common nonfunctional alleles are $* 3, * 4, * 5$, and $* 6$. The basis for altered allele function comprises a diversity of mechanisms that include SNPs, gene deletions and multiplications, insertional mutations, and gene conversions. Interethnic genotypic and phenotypic frequency variations exist: PM frequency is roughly $1 \%$ among Asian groups and 5\%-10\% among Caucasians. ${ }^{59}$ Also, CYP2D6 activities among genotype groups are lower for black Africans than for whites and Asians. ${ }^{60}$

Clinical relevance for CYP2D6 polymorphism is clearly established: PMs are more likely than EMs to experience toxicity due to certain antiarrhythmics, antidepressants, and neuroleptics and are less likely to benefit from opioid analgesics. ${ }^{61}$ For example, codeine is demethylated by CYP2D6 to produce morphine and causes greater analgesia and physiologic effects in EMs than in PMs. ${ }^{62,63}$ CYP2D6 also metabolizes the narrow-index tricyclic antidepressants (TCAs). ${ }^{64}$ Pharmacokinetic studies show a clear gene-dose effect for the plasma concentration-versus-time profile of the TCA nortriptyline. At constant dose, area-under-the-curve is highest in subjects without functional CYP2D6 alleles and decreases as number of functional alleles increases. ${ }^{65}$

TCAs and selective serotonin reuptake inhibitors (SSRIs) ameliorate functional bowel disease symptoms. Amitryptiline is used to treat visceral hypersensitivity in irritable bowel syndrome (IBS) ${ }^{66}$ and idiopathic fecal 
incontinence. ${ }^{67}$ It is unclear whether CYP2D6 genotype or phenotype correlates with IBS patient response to TCAs.

As with TPMT, nongenetic factors may alter the CYP2D6 genotype-phenotype correlation. Among the drugs known to cause "phenocopying" to PM status are the antiarrythmic quinidine ${ }^{68}$ and SSRIs. ${ }^{69}$ While coadministration of multiple antidepressants is not generally recommended, combined TCA-SSRI therapy can increase TCA plasma levels in rapid metabolizers. ${ }^{70}$ This approach may improve TCA efficacy for CYP2D6 rapidmetabolizers with depression, a common diagnosis among IBS patients. ${ }^{71}$

Labels for several drugs suggest dose reduction for CYP2D6 PMs but do not recommend CYP2D6 genotyping or phenotyping. Indeed, CYP2D6 genotyping and phenotyping are not routinely performed in any clinical setting due to the routine "start low, go slow" practice of dose escalation based upon blood levels or clinical endpoints.

\section{CYP2C19}

Polymorphic CYP2C19 activity is well described and most humans are inferred to be CYP2C19 EMs. ${ }^{59}$ PM status is conferred by an absence of functional alleles. Nine allelic variants have been identified to date and designated $* 2 A, * 2 B, * 3, * 4, * 5 A, * 5 B, * 6$, *7, and $* 8 .{ }^{58}$ None produces a functional enzyme. Significant interethnic differences are apparent: roughly $4 \%, 14 \%$, and $3 \%$ of blacks of African descent, Chinese individuals, and Caucasians, respectively, are genotyped or phenotyped as PMs. Frequencies of PM alleles also vary significantly between populations. ${ }^{59}$ Like CYP2D6, CYP2C19 is not easily assayed in peripheral tissues, so phenotype is obtained by administration of probe drugs such as mephenytoin or omeprazole. ${ }^{59}$

Proton pump inhibitors (PPIs) are metabolized by CYP2C19. ${ }^{72}$ Screening proponents note CYP2C19 genotype association with the effects of omeprazole and lansoprazole upon intragastric $\mathrm{pH}$ in $H$. pylori-negative subjects $^{73,74}$ and with $H$. pylori eradication after treatment with omeprazole or lansoprazole combined with amoxycillin and clarithromycin. ${ }^{75}$ Patients classified as PMs by CYP2C19 genotype have the highest cure rates, followed in order by heterozygous and homozygous EMs.

Several observations call into question the need for CYP2C19 screening. While rates of endoscopically confirmed gastroesophageal reflux disease resolution associate with genotype, complete acid inhibition is achieved in healthy subjects by frequent administration of highdose lansoprazole ${ }^{76}$ and $H$. pylori is eradicated by retreat- ment with high-dose lansoprazole and amoxycillin, ${ }^{75}$ irrespective of genotype. Metabolism of rabeprazole, a newer PPI, is less dependent upon CYP2C19 than is that of older PPIs and is thus less susceptible to polymorphic genetic effects. ${ }^{77}$ Also, greater governmental and industrial interest in determinants of toxicity as opposed to those for efficacy may dampen prospects for widespread CYP2C19 assessment.

\section{CYP3A}

Members of the CYP3A subfamily metabolize the majority of drugs available on the market. ${ }^{59,78}$ In adults, the CYP3A4 and CYP3A5 isozymes are the only subfamily members that are expressed in the liver and intestines. ${ }^{79}$ Interindividual variation in CYP3A activity measured with probes such as the erythromycin breath test $^{74}$ accounts largely for interpatient differences in the pharmacokinetics of many drugs that include cyclosporin $\mathrm{A},{ }^{80}$ midazolam ${ }^{81}$ and docetaxel. ${ }^{82}$ It appears that nearly everyone expresses CYP3A4 and a genetic basis for marked interpatient variation in activity has not been identified. In contrast, CYP3A5 expression is polymorphic and population differences abound: among some groups (e.g., Caucasians), CYP3A5 is expressed by less than $10 \%$ but is expressed by the majority among other populations (e.g., African-Americans). ${ }^{83,84}$ Interpopulation differences appear to reflect differences in the frequency of the functional CYP3A5*1 allele. CYP3A5 expression may be greater than that of CYP3A4 in CYP3A5-expressing individuals and CYP3A5 substrate specificity is similar to that of CYP3A4, so it is possible that CYP3A5 polymorphism is the major contributor to variation in aggregate $\mathrm{CYP} 3 \mathrm{~A}$ activity. ${ }^{83}$ The clinical implications of CYP3A5 polymorphism are largely unexplored.

\section{DPD}

For the treatment of metastatic colorectal cancer after surgical resection, 5-fluorouracil (5-FU) is a mainstay. ${ }^{85}$ Dihydropyrimidine dehydrogenase (DPD), which is encoded by the DPYD gene, is the rate-limiting enzyme in 5-FU catabolism. ${ }^{86}$ DPD activity is at least partially lacking in 3\%-5\% of people and its absence is associated with severe toxicity and death among 5-FUtreated cancer patients. ${ }^{87}$ DPD deficiency may largely reflect the influence of the $D P Y D * 2 A$ allele, which produces an inactive enzyme. ${ }^{88}$ While a number of genetic variations have been associated with decreased DPD activity, ${ }^{89,90}$ their population distributions and contributions to phenotypic variability have yet to be demonstrated. It is likely that screening for multiple DPYD 
variants will be necessary in order to provide sufficient sensitivity to testing. ${ }^{91}$

\section{UGT1A1}

The UGTs catalyze the conjugation of a variety of drugs that include the camptothecin analogues. ${ }^{92}$ The unconjugated hyperbilirubinemia of Gilbert's syndrome results mainly from deficiency of uridine diphosphateglucuronosyltransferase 1A1 (UGT1A1) due to a TA insertion in the $U G T 1 A 1$ promoter region that produces the $U G T 1 A 1 * 28$ allele. ${ }^{93} U G T 1 A 1 * 28$ has been associated with decreased glucuronidation of irinotecan's active and toxic metabolite $\mathrm{SN}-38$ in human liver samples ${ }^{94}$ and with altered $\mathrm{SN}-38$ disposition, severe neutropenia, and diarrhea in retrospective ${ }^{95}$ and prospective studies ${ }^{96}$ of patients with various solid tumors. While Gilbert's syndrome is often undiagnosed in adults, it is unknown whether UGT1A1 genotype or enzyme activity provides useful information about patients already known to have unconjugated hyperbilirubinemia.

\section{Pharmacogenetics in Perspective}

A widely cited meta-analysis estimates that in 1994 serious adverse drug reactions (ADRs) occurred in $>2$ million hospitalized patients and caused more than 100,000 fatalities, making ADRs between the fourth and sixth leading cause of death. ${ }^{97}$ Pharmacogenetics has been promoted as a means of reducing ADRs and drug failures. Some have even suggested that an individual's relevant genetic information might be stored and used to select optimal drugs and doses for any disease.

There are few obvious obstacles to applying genetic technology to this end. The equipment necessary to perform genetic testing is now available at most major medical centers where genetic predisposition to a variety of diseases, including hereditary hemochromatosis and $\alpha_{1}$ antitrypsin deficiency, is routinely assessed. Every American newborn is screened for a minimum of 4 heritable diseases through analysis of a drop of blood obtained by heel stick. ${ }^{98}$ There is thus ample precedent in clinical medicine to screen for inherited conditions when diagnosis is in an individual's best interest. Screening for optimal drug response determinants is consistent with this precedent.

Why, then, is clinical application of pharmacogenetics only slowly occurring? The examples reviewed here demonstrate the utility and limitations of pharmacogenetic screening. One such limitation is that a gene usually has many alleles, so that few genetic tests approach $100 \%$ sensitivity. Furthermore, a drug's effect may reflect the actions of multiple metabolizing enzymes, transporters, and targets, all of which may be polymorphically expressed. Most metabolic pathways are also affected by a variety of nongenetic factors that include drug interactions, disease, diet, and age. Thus, strong association between a particular genotype and a drug response in population studies does not necessarily relate the confidence with which the test may predict an individual patient's response.

The predictive shortcomings of genotype are partially overcome by phenotyping assays that measure the actual target activity. But with the exception of TPMT, most target enzymes and transporters are not present in blood or other easily accessible tissues. Phenotyping might therefore involve tissue biopsy or probe drug administration. In many instances, monitoring plasma levels of the therapeutic drug or its metabolites might be preferable. This, in effect, would be the use of the drug as its own probe. This approach generates more relevant information than enzyme-specific probes since most drugs have several potentially variable elimination pathways. Pharmacokinetic diversity can therefore reflect variations in pathways besides those targeted by a probe. Ultimately, multiple-probe "cocktails" might address this problem, but tests would need to be safe and amenable to rapid administration and analysis to be practical for most physicians.

The time-honored "start low, go slow" approach to variable drug response is to monitor clinical response to slowly escalating drug doses. This provides the advantage of accounting for both pharmacokinetic and pharmacodynamic variables. But in many instances, it may result in prolonged intervals of ineffective treatment. With some cancer chemotherapies, the "start low" approach may also provoke multidrug resistance.

In summary, pharmacogenetic testing will enter mainstream clinical practice over the next decade. This will be particularly evident in fields like psychiatry and oncology in which many medications have narrow therapeutic indices, but will probably also be evident in the typical gastroenterology practice. When selecting a drug and its initial dose, the patient's relevant genotype or pharmacokinetic/pharmacodynamic phenotype will supplement but not replace traditional clinical parameters such as age, renal function, or body size. In many cases, current dosing paradigms such as the "start low, go slow" approach will be modified but not abandoned.

\section{References}

1. Kalow W. Pharmacogenetics, pharmacogenomics and pharmacobiology. Clin Pharmacol Ther 2001;70:1-4.

2. Ozdemir V, Shear NH, Kalow W. What will be the role of pharmacogenetics in evaluating drug safety and minimising adverse effects? Drug Saf 2001;24:75-85. 
3. Roden DM, George AL. The genetic basis of variability in drug responses. Nature Rev Drug Disc 2002;1:37-44.

4. Evans WE, McLeod HL. Pharmacogenomics-drug disposition, drug targets, and side effects. N Engl J Med 2003;348:538-549.

5. Bell R. What can we learn from herceptin trials in metastatic breast cancer? Oncology 2002;63(Suppl 1):39-46.

6. Capdeville R, Buchdunger E, Zimmermann J, Matter A. Glivec (STI571, imatinib), a rationally developed, targeted anticancer drug. Nature Rev Drug Disc 2002;1:493-502.

7. Weinshilboum RM. Inheritance and drug response. N Engl J Med 2003;348:529-537.

8. Relling MV, Dervieux T. Pharmacogenetics and cancer therapy. Nature Rev Cancer 2001;1:99-108.

9. Sandborn WJ, Sutherland L, Pearson D, May G, Modigliani R, Prantera C. Azathioprine or 6-mercaptopurine for induction of remission in Crohn's disease. Cochrane Database Syst Rev 2002.

10. Pearson D, May G, Fick G, Sutherland L. Azathioprine for maintenance of remission in Crohn's disease. Cochrane Database Syst Rev 2002.

11. Sandborn WJ. Azathioprine: state of the art in inflammatory bowel disease. Scand J Gastroenterol 1998;33:92-99.

12. Nielsen $\mathrm{OH}$, Vainer $\mathrm{B}$, Rask-Madsen J. Review article: the treatment of inflammatory bowel disease with 6-mercaptopurine or azathioprine. Aliment Pharmacol Ther 2001;15:1699-1708.

13. Wiesner R, Rabkin J, Klintmalm G, McDiarmid S, Langnas A, Punch J, et al. A randomized double-blind comparative study of mycophenolate mofetil and azathioprine in combination with cyclosporine and corticosteroids in primary liver transplant recipients. Liver Transpl 2001;7:442-450.

14. Johnson PJ, McFarlane IG, Williams R. Azathioprine for long-term maintenance of remission in autoimmune hepatitis. N Engl J Med 1995;333:958-963.

15. Lennard L. The clinical pharmacology of 6-mercaptopurine. Eur J Clin Pharmacol 1992;43:329-339.

16. Lennard L. Therapeutic drug monitoring of cytotoxic drugs. $\mathrm{Br} J$ Clin Pharmacol 2001;52:75S-87S.

17. Evans WE. Thiopurine S-methyltransferase: a genetic polymorphism that affects a small number of drugs in a big way. Pharmacogenetics 2002;12:421-423.

18. Grant DM, Tang BK, Kalow W. Variability in caffeine metabolism. Clin Pharmacol Ther 1983;33:591-602.

19. Relling MV, Hancock ML, Rivera GK, Sandlund JT, Ribeiro RC, Krynetski EY, et al. Mercaptopurine therapy intolerance and heterozygosity at the thiopurine S-methyltransferase gene locus. J Natl Cancer Inst 1999;91:2001-2008.

20. Evans WE, Horner M, Chu YQ, Kalwinsky D, Roberts WM. Altered mercaptopurine metabolism, toxic effects, and dosage requirement in a thiopurine methyltransferase-deficient child with acute lymphocytic leukemia. J Pediatr 1991;119:985-989.

21. Evans WE, Hon YY, Bomgaars L, Coutre S, Holdsworth M, Janco $\mathrm{R}$, et al. Preponderance of thiopurine S-methyltransferase deficiency and heterozygosity among patients intolerant to mercaptopurine or azathioprine. J Clin Oncol 2001;19:2293-2301.

22. Lennard L, Van Loon JA, Lilleyman JS, Weinshilboum RM. Thiopurine pharmacogenetics in leukemia: correlation of erythrocyte thiopurine methyltransferase activity and 6-thioguanine nucleotide concentrations. Clin Pharmacol Ther 1987;41:18-25.

23. Lennard L, Van Loon JA, Weinshilboum RM. Pharmacogenetics of acute azathioprine toxicity: relationship to thiopurine methyltransferase genetic polymorphism. Clin Pharmacol Ther 1989; 46:149-154.

24. Krynetski EY, Evans WE. Pharmacogenetics of cancer therapy: getting personal. Am J Hum Genet 1998;63:11-16.

25. Weinshilboum RM, Sladek SL. Mercaptopurine pharmacogenetics: monogenic inheritance of erythrocyte thiopurine methyltransferase activity. Am J Hum Genet 1980;32:651-662.
26. MayoAccess Test Catalog. http://216.245.167.14:81/MALHTML/ 80291.html. Accessed 11/10/2002.

27. McLeod HL, Lin JS, Scott EP, Pui CH, Evans WE. Thiopurine methyltransferase activity in American white subjects and black subjects. Clin Pharmacol Ther 1994;55:15-20.

28. Jang IJ, Shin SG, Lee KH, Yim DS, Lee MS, Koo HH, et al. Erythrocyte thiopurine methyltransferase activity in a Korean pop ulation. Br J Clin Pharmacol 1996;42:638-641.

29. Park-Hah JO, Klemetsdal B, Lysaa R, Choi KH, Aarbakke J. Thiopurine methyltransferase activity in a Korean population sample of children. Clin Pharmacol Ther 1996;60:68-74.

30. Lee EJ, Kalow W. Thiopurine S-methyltransferase activity in a Chinese population. Clin Pharmacol Ther 1993;54:28-33.

31. Weinshilboum RM. Thiopurine pharmacogenetics: clinical and molecular studies of thiopurine methyltransferase. Drug Metab Dispos 2001;29:605.

32. Tai HL, Fessing MY, Bonten EJ, Yanishevski Y, d'Azzo A, Krynetski EY, et al. Enhanced proteasomal degradation of mutant human thiopurine S-methyltransferase (TPMT) in mammalian cells: mechanism for TPMT protein deficiency inherited by TPMT $* 2$, TPMT*3A, TPMT*3B, or TPMT*3C. Pharmacogenetics 1999;9:641-650.

33. Szumlanski CL, Otterness DM, Her C, Lee D, Brandriff B, Kelsell $D$, et al. Thiopurine methyltransferase pharmacogenetics: human gene cloning and characterization of a common polymorphism. DNA Cell Biol 1996;15:17-30.

34. Otterness DM, Szumlanski CL, Lennard L, Klemetsdal B, Aarbakke J, Park-Hah JO, et al. Human thiopurine methyltransferase pharmacogenetics: gene sequence polymorphisms. Clin Pharmacol Ther 1997;62:60-73.

35. McLeod HL, Krynetski EY, Relling MV, Evans WE. Genetic polymorphism of thiopurine methyltransferase and its clinical relevance for childhood acute lymphoblastic leukemia. Leukemia 2000;14:567-572.

36. Collie-Duguid ESR, Pritchard SC, Powrie RH, Sludden J, Collier $\mathrm{DA}$, Li T, et al. The frequency and distribution of thiopurine methyltransferase alleles in Caucasian and Asian populations. Pharmacogenetics 1999;9:37-42.

37. Yan L, Zhang S, Eiff B, Szumlanski CL, Powers M, O'Brien JF, et al. Thiopurine methyltransferase polymorphic tandem repeat: genotype-phenotype correlation analysis. Clin Pharmacol Ther 2000;68:210-219.

38. Yates CR, Krynetski EY, Loennechen T, Fessing MY, Tai HL, Pui $\mathrm{CH}$, et al. Molecular diagnosis of thiopurine S-methyltransferase deficiency: genetic basis for azathioprine and mercaptopurine intolerance. Ann Intern Med 1997;126:608-614.

39. Andersen JB, Szumlanski CL, Weinshilboum RM, Schmiegelow K. Pharmacokinetics, dose adjustments, and 6-mercaptopurine/ methotrexate drug interactions in two patients with thiopurine methyltransferase deficiency. Acta Paediatr 1998;87:108-111.

40. Langley PG, Underhill J, Tredger JM, Norris S, McFarlane IG. Thiopurine methyltransferase phenotype and genotype in relation to azathioprine therapy in autoimmune hepatitis. J Hepatol 2002; 37:441-447.

41. Black AJ, McLeod HL, Capell HA, Powrie RH, Matowe LK, Pritchard SC, et al. Thiopurine methyltransferase genotype predicts therapy-limiting severe toxicity from azathioprine. Ann Intern Med 1998;129:716-718.

42. Campbell S, Kingstone K, Ghosh S. Relevance of thiopurine methyltransferase activity in inflammatory bowel disease patients maintained on low-dose azathioprine. Aliment Pharmacol Ther 2002;16:389-398.

43. Dubinsky MC, Lamothe S, Yang HY, Targan SR, Sinnett D, Theoret $Y$, et al. Pharmacogenomics and metabolite measurement for 6-mercaptopurine therapy in inflammatory bowel disease. Gastroenterology 2000;118:705-713.

44. Cuffari C, Theoret Y, Latour S, Seidman EG. 6-Mercaptopurine 
metabolism in Crohn's disease: correlation with efficacy and toxicity. Gut 1996;39:401-406.

45. Schwab M, Schäffeler E, Marx C, Fischer C, Lang T, Behrens C, et al. Azathioprine therapy and adverse drug reactions in patients with inflammatory bowel disease: impact of thiopurine S-methyltransferase polymorphism. Pharmacogenetics 2002;12:429-436.

46. Colombel JF, Ferrari N, Debuysere H, Marteau P, Gendre JP, Bonaz B, et al. Genotypic analysis of thiopurine S-methyltransferase in patients with Crohn's disease and severe myelosuppression during azathioprine therapy. Gastroenterology 2000; 118:1025-1030.

47. Cunliffe RN, Scott BB. Review article: monitoring for drug sideeffects in inflammatory bowel disease. Aliment Pharmacol Ther 2002;16:647-662.

48. Sandborn WJ. Rational dosing of azathioprine and 6-mercaptopurine. Gut 2001;48:591-592.

49. Lewis LD, Benin A, Szumlanski CL, Otterness DM, Lennard L, Weinshilboum RM, et al. Olsalazine and 6-mercaptopurinerelated bone marrow suppression: a possible drug-drug interaction. Clin Pharmacol Ther 1997;67:464-465.

50. Lowry PW, Franklin CL, Weaver AL, Szumlanski CL, Mays DC, Loftus EV, et al. Leucopenia resulting from a drug interaction between azathioprine of 6-mercaptopurine and mesalamine, sulphasalazine, or balsalazide. Gut 2001;49:656-664.

51. Lysaa RA, Giverhaug T, Wold HL, Aarbakke J. Inhibition of human thiopurine methyltransferase by furosemide, bendroflumethiazide and trichlormethiazide. Eur J Clin Pharmacol 1996;49:393396.

52. Lennard L, Lilleyman JS, Van Loon JA, Weinshilboum RM. Genetic variation in response to 6-mercaptopurine for childhood acute lymphoblastic leukaemia. Lancet 1990;336:225-229.

53. Giverhaug $T$, Loennechen $T$, Aarbakke J. The interaction of 6-mercaptopurine (6-MP) and methotrexate (MTX). Gen Pharmacol 1999;33:341-346.

54. Cuffari C, Hunt S, Bayless T. Utilisation of erythrocyte 6-thioguanine metabolite levels to optimise azathioprine therapy in patients with inflammatory bowel disease. Gut 2001;48:642-646.

55. Lamers CBHW, Griffioen G, van Hogezand RA, Veenendaal RA. Azathioprine: an update on clinical efficacy and safety in inflammatory bowel disease. Scand J Gastroenterol 1999;230(Suppl): 111-115.

56. Lennard L. TPMT in the treatment of Crohn's disease with azathioprine. Gut 2002;51:143-146.

57. Meeting of the Clinical Pharmacology Subcommittee of the Advisory Committee for Pharmaceutical Science, U.S. Food and Drug Administration Center for Drug Evaluation and Research. October 23, 2002. http://www.fda.gov/ohrms/dockets/ac/02/transcripts/ 3898T1.htm.

58. Human Cytochrome P450 (CYP) Allele Nomenclature Committee. http://www.imm.ki.se/CYPalleles/. Accessed October 20, 2002.

59. Xie H-G, Kim RB, Wood AJJ, Stein CM. Molecular basis of ethnic differences in drug disposition and response. Annu Rev Pharmacol Toxicol 2001;41:815-850.

60. Bertilsson L. Current status: pharmacogenetics/drug metabolism. In: Kalow W, Meyer UA, Tyndale RF, eds. Pharmacogenomics. New York: Marcel Dekker, Inc., 2001:33-50.

61. Meyer UA. Drugs in special patient groups: clinical importance of genomics in drug effects. In: Carruthers GS, Hoffmann BB, Melmon KL, Nierenberg DW, eds. Melmon and Morelli's Clinical Pharmacology. New York: McGraw-Hill, 2000:1179-1205.

62. Caraco Y, Sheller J, Wood AJ. Pharmacogenetic determination of the effects of codeine and prediction of drug interactions. J Pharmacol Exp Ther 1996;278:1165-1174.

63. Poulsen L, Brosen K, Arendt-Nielsen L, Gram LF, Sindrup SH. Codeine and morphine in extensive and poor metabolizers of sparteine: pharmacokinetics, analgesic effect and side effects. Eur J Clin Pharmacol 1996;51:289-295.
64. Poolsup N, Po LW, Knight TL. Pharmacogenetics and psychopharmacotherapy. J Clin Pharm Ther 2000;25:197-220.

65. Dalén P, Dahl M-L, Bernal Ruiz ML, Nordin J, Bertilsson L. 10Hydroxylation of nortriptyline in Caucasians with $0,1,2,3$, and 13 functional CYP2D6 genes. Clin Pharmacol Ther 1998;63: 444-452.

66. Poitras P, Riberdy Poitras M, Plourde V, Boivin M, Verrier P. Evolution of visceral sensitivity in patients with irritable bowel syndrome. Dig Dis Sci 2002;47:914-920.

67. Santoro GA, Eitan BZ, Pryde A, Bartolo DC. Open study of lowdose amitriptyline in the treatment of patients with idiopathic fecal incontinence. Dis Colon Rectum 2000;43:1676-1682.

68. Giao PT, de Vries PJ. Pharmacokinetic interactions of antimalarial agents. Clin Pharmacokinet 2001;40:343-373.

69. Lam YW, Gaedick A, Ereshefsky L, Alfaro CL, Simpson J. CYP2D6 inhibition by selective serotonin reuptake inhibitors: analysis of achievable steady-state plasma concentrations and the effect of ultrarapid metabolism at CYP2D6. Pharmacotherapy 2002;28: 1001-1006.

70. Kraus RP, Diaz P, McEachran A. Managing rapid metabolizers of antidepressants. Depress Anxiety 1996;4:320-327.

71. Jackson JL, O'Malley PG, Tomkins G, Balden E, Santoro J, Kroenke K. Treatment of functional gastrointestinal disorders with antidepressant medications: a meta-analysis. Am J Med 2000;108:65-72.

72. Dojo M, Azuma T, Saito T, Ohtani M, Muramatsu A, Kuriyama M. Effects of CYP2C19 gene polymorphism on cure rates for Helicobacter pylori infection by triple therapy with proton pump inhibitor (omeprazole or rabeprazole), amoxycillin and clarithromycin in Japan. Dig Liver Dis 2001;33:671-675.

73. Furuta T, Shirai N, Xiao F, Ohashi K, Ishizaki T. Effect of high-dose lansoprazole on intragastric $\mathrm{pH}$ in subjects who are homozygous extensive metabolizers of cytochrome P4502C19. Clin Pharmacol Ther 2001;70:484-492.

74. Furuta T, Ohashi K, Kosuge K, Zhao X-J, Takashima M, Kimura M, et al. CYP2C19 genotype status and effect of omeprazole on intragastric pH in humans. Clin Pharmacol Ther 1999;65:552561.

75. Furuta $T$, Shirai $N$, Takashima M, Fang $X$, Hanai $H$, Sugimura $H$, et al. Effect of genotypic differences in CYP2C19 on cure rates for Helicobacter pylori infection by triple therapy with a proton pump inhibitor, amoxicillin, and clarithromycin. Clin Pharmacol Ther 2001;69:158-168.

76. Furuta T, Shirai N, Watanabe F, Honda S, Takeuchi K, lida T, et al. Effect of cytochrome P4502C19 genotypic differences on cure rates for gastroesophageal reflux disease by lansoprazole. Clin Pharmacol Ther 2002;72:453-460.

77. Ishizaki T, Horai Y. Review article: cytochrome P450 and the metabolism of proton pump inhibitors-emphasis on rabeprazole. Aliment Pharmacol Ther 1999;13:27-36.

78. Watkins PB. Noninvasive tests of CYP3A enzymes. Pharmacogenetics 1998;4:184.

79. Wrighton SA, Brian WR, Sari MA, Iwasaki M, Guengerich FP, Raucy $\mathrm{JL}$, et al. Studies on the expression and metabolic capabilities of human liver cytochrome P450IIIA5 (HLp3). Mol Pharmacol 1990;38:207-213.

80. Turgeon DK, Leichtman AB, Lown KS, Normelle DP, Deeb GM, Merion RM, et al. P450IIIA (CYP3A) activity and cyclosporin A dosing in renal and cardiac transplant recipients. Clin Pharmacol Ther 1994;56:253-260.

81. Thummel KE, O'Shea D, Paine MF, Shen DD, Kunze KL, Perkins $J D$, et al. Oral first-pass elimination of midazolam involves both gastrointestinal and hepatic CYP3A-mediated metabolism. Clin Pharmacol Ther 1996;59:491-502.

82. Hirth J, Watkins PB, Strawderman MS, Schott A, Bruno R, Baker L. The effect of an individual's cytochrome CYP3A4 activity of docetaxel clearance. Clin Cancer Res 2000;6:1255-1258. 
83. Kuehl P, Zhang J, Lin Y, Lamba J, Assem M, Schuetz J, et al. Sequence diversity in CYP3A promoters and characterization of the genetic basis of polymorphic CYP3A5 expression. Nat Genet 2001;27:383-391.

84. Hustert E, Haberl M, Burk O, Wolbold R, He Y-Q, Klein K, et al. The genetic determinants of the CYP3A5 polymorphism. Pharmacogenetics 2001;11:773-779.

85. Moertel CG. Drug therapy: chemotherapy for colorectal cancer. N Engl J Med 1994;330:1136-1142.

86. Diasio RB, Harris BE. Clinical pharmacology of 5-fluorouracil. Clin Pharmacokinet 1989;16:215-237.

87. Lu ZH, Zhang RW, Diasio RB. Dihydropyrimidine dehydrogenaseactivity in human peripheral-blood mononuclear-cells and liverpopulation characteristics, newly identified deficient patients, and clinical implication in 5-fluorouracil chemotherapy. Cancer Res 1993;53:5433-5438.

88. Raida M, Schwabe W, Häusler P, Van Kuilenburg ABP, Van Gennip $\mathrm{AH}$, Behnke D, et al. Prevalence of a common point mutation in the dihydropyrimidine dehydrogenase (DPD) gene within the 5'-splice donor site of intron 14 in patients with severe 5-fluorouracil (5-FU)-related toxicity compared with controls. Clin Cancer Res 2001;7:2832-2839.

89. Johnson MR, Wang KS, Diasio RB. Profound dihydropyrimidine dehydrogenase deficiency resulting from a novel compound heterozygote genotype. Clin Cancer Res 2002;8:768-774.

90. McLeod HL, Collie-Duguid ES, Vreken P, Johnson MR, Wei X, Sapone A, et al. Nomenclature for human DPYD alleles. Pharmacogenetics 1998:8:455-459.

91. Innocenti F, Ratain MJ. Update on pharmacogenetics in cancer chemotherapy. Eur J Cancer 2002;38:639-644.
92. Burchell B, Soars M, Monaghan G, Cassidy A, Smith D, Ethell B. Drug-mediated toxicity caused by genetic deficiency of UDPglucuronosyltransferases. Toxicol Lett 2000;112-113:333-340.

93. Bosma PJ, Chowdhury JR, Bakker C, Gantla S, Deboer A, Oostra $\mathrm{BA}$, et al. The genetic basis of the reduced expression of bilirubin UDP-glucuronosyltransferase 1 in Gilbert's Syndrome. N Engl J Med 1995;333:1171-1175.

94. Iyer L, Hall D, Das S, Mortell MA, Ramírez J, Kim S, et al. Phenotype-genotype correlation of in vitro SN-38 (active metabolite of irinotecan) and bilirubin glucuronidation in human liver tissue with UGT1A1 promoter polymorphism. Clin Pharmacol Ther 1999;65:576-582.

95. Ando $\mathrm{Y}$, Saka H, Ando M, Sawa T, Muro K, Ueoka H, et al. Polymorphisms of UDP-Glucuronosyltransferase gene and irinotecan toxicity: a pharmacogenetic analysis. Cancer Res 2000; 60:6921-6926.

96. Iyer L, Das S, Janisch L, Wen M, Ramírez J, Karrison T, et al. UGT1A1*28 polymorphism as a determinant of irinotecan disposition and toxicity. Pharmacogenomics J 2002;2:43-47.

97. Lazarou J, Pomeranz BH, Corey PN. Incidence of adverse drug reactions in hospitalized patients. JAMA 1998;279:1200-1205

98. Marshall E. Fast technology drives new world of newborn screening. Science 2001;294:2272-2274.

Received December 17, 2002. Accepted February 13, 2003.

Address requests for reprints to: Paul B. Watkins, M.D., General Clinical Research Center, University of North Carolina at Chapel Hill, Chapel Hill, North Carolina 27514. e-mail: pbwatkins@med.unc.edu Supported in part by RR00046. 